\section{OSTEOMA OF THE FRONTAL SINUS}

$$
\text { W. W. BOARDMAN, M.D. }
$$$$
\text { AND }
$$

MARY M. DONOVAN, M.D.

Associate Professor of Medicine and Assistant in Medicine, Respectively, Leland Stanford Junior University School of Medicine

$$
\text { SAN FRANCISCO }
$$

The occurrence of osteoma of the frontal sinus is relatively infrequent, as may be judged from the fact that Sewall, ${ }^{1}$ after carefully reviewing the literature, found only ninety-two cases. In these cases the diagnosis was based on the presence of anatomic deformities secondary to the osteoma; in only a few had the roentgen ray been used to confirm the clinical impression, and in none had the condition been primarily diagnosed roentgenographically.

During the past six months the following two cases of clinically unsuspected osteoma of the frontal sinus have been discovered in the routine examination of skull plates.

CASE 1.-A man entered the Stanford University Medical School Hospital, complaining of very severe headaches of long duration. In the early stages these had been frontal, but
'THE SPREADING POWER OF COAL OILS *

\section{TORALD SOLLMANN, M.D. CLEVELAND}

P. N. Leech ${ }^{1}$ and $\mathrm{I}^{2}$ independently observed that the addition of a little asphalt to melted paraffin greatly lowered its surface tension toward water, so that a very much thinner and more even film than with pure paraffin is formed, and very much more rapidly. In reflecting on this phenomenon, it occurred to me that it might be utilized to secure rapid and extensive spreading of the oil in fighting mosquito larvae, thus increasing the efficiency and lowering the cost of the oil treatment.

Experiments showed that kerosene has a low spreading power, and that this is actually enormously increased by the addition of asphalt. If kerosene is dropped on a dish of water, it collects into rather small plaques, and spreads very slowly, if at all. If 0.1 per cent. or more of asphalt varnish ("B-asphaltum, Cleveland Window Glass Company") has been added, it spreads at once over the entire surface of the water. Similar results were observed with gasoline.

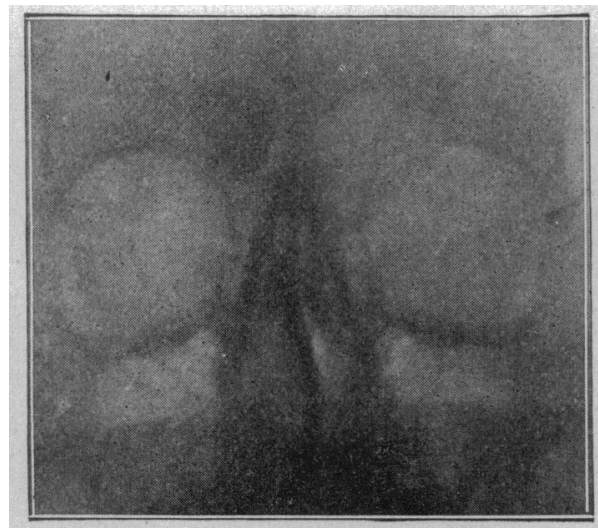

Fig. 1 (Case 1).--Anteroposterior view of osteoma of frontal sinus. The tumor occupies the right frontal sinus, aithough not completely filling it. of late they had been principally occipital. Diffuse brain tumor seemed to be the clinical diagnosis. However, lateral stereoscopic skull plates showed an abnormal area of density in the region of the frontal sinus. Examination of sinus plates showed a uniformly dense, sharply outlined shadow in the right frontal sinus. On these findings a diagnosis of osteoma of the frontal sinus was made. At operation a hard, bony tumor was found firmly wedged into the sinus. It was successfully removed and the patient has been completely relieved of all symptoms.

CASE 2.-A young man came complaining of convulsive attacks, simulating epilepsy, but with no objective deformities suggesting osteoma. Examination of plates of the skull showed a large, dense, irregular shadow occupying the frontal sinus region, extending downward into the ethmoid region and backward into the cranial vault. Operation again confirmed the diagnosis of osteoma of the frontal sinus, but the patient died of a complicating meningitis.

The lesson to be drawn from these cases is not that osteoma of the frontal sinus can be diagnosed by the roentgen ray-that is self-evident-but that roentgenographic study of all doubtful head cases should be made as a routine."

1. Sewall, E. D.: Ann. Otol., Rhinol, and Laryngol., 1918, 27, 275 2. In addition to the reference already given, the following will be found of interest:

De Taranto, I. M.: Les osteomes de l'orbit, thèse de Paris, 1901

Perthes, George: Arch. f. klin. Chir., 1904, 72, 1022

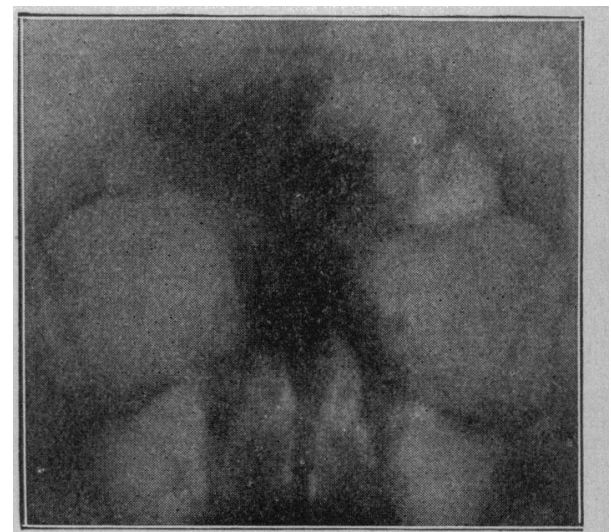

Fig. 3 (Case 2).-Anteroposterior view of same case. The tumor appears to involve one of the frontal sinuses more than the other. Its invasion of the ethmoid region shows plainly.

However, unrefined oils generally spread perfectly without the addition of asphalt. They presumably already contain sufficient asphalt-like products.

The following crude oils spread perfectly without the addition of asphalt:

Pennsylvania Lower District Crude.

Light Tiona Crude.

Kansas-Oklahoma Crude.

Residue oil left after distillation of the lighter product. A sample of "No. 4 Road Oil" did not spread.

\title{
SUMMARY
}

The "spreading power" of oils on water is important in their use against mosquito larvae. It should therefore be ascertained, at least by the rough test herein described.

The spreading power depends largely on the presence of asphalt-like products. Most crude oils contain these in sufficient quantity. Some, however, and especially refined oils, need the addition of asphalt. Kerosene requires about 0.1 per cent of asphalt varnish.

* From the Department of Pharmacology, Western Reserve Univer. sity School of Medicine.

1. Leech, P. N.: "Ambrine" and Paraffin Films, The Journal A. M. A., May 19, 1917, p. 1497 .

2. Sollmann, Torald: Suggested Formulas for Paraffin Films, THE Journal A. M. A., April 7, 1917, p. 1037. 